\title{
Field study on thermal environment and climate adaptability of Turpan houses
}

\author{
Zhaohui Zhang ${ }^{1, \mathrm{a}}$, Wenfang $\mathrm{He}^{1}$ and Lin Zhao ${ }^{2}$ \\ ${ }^{1}$ School of Architecture, Xi'an University of Architecture and Technology, 710055 Xi'an ShanXi, China \\ ${ }^{2}$ School of Architecture, Qingdao University of Technology, 266033 Qingdao ShanDong, China
}

\begin{abstract}
In this research a traditional house and a comfortable house are chosen, their thermal environment including air temperatures, air relative humidity, and surface temperature of walls are tested, and test result are analysed. In addition, the thermal advantages and shortages of these two houses are summarized, and the climate adaptability is obtained. Therefore, some advice is put forward for the sustainable development of local vernacular building.

Keywords: traditional house; climate Adaptability; thermal environment; turpan; field study.
\end{abstract}

\section{Introduction}

As located in northwest of china, at the edge of Taklimakan desert, and in altitude of minus 100 meters, Turpan is one of the most arid region in the world, where always suffer scorching summer and cold winter. This typical climate is well-know from its other name "Fired Island "[1].

For more comfortable living, villagers used to build house by earth. With the heavy earth envelope made by adobe wall and soil roof, the indoor thermal environment of traditional house is known as cool in summer and warm in winter[2].

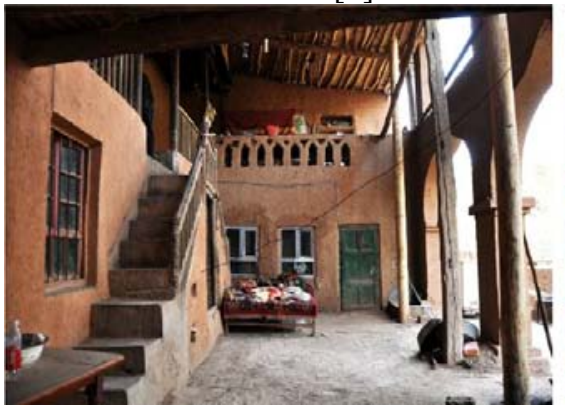

(a) Traditional house

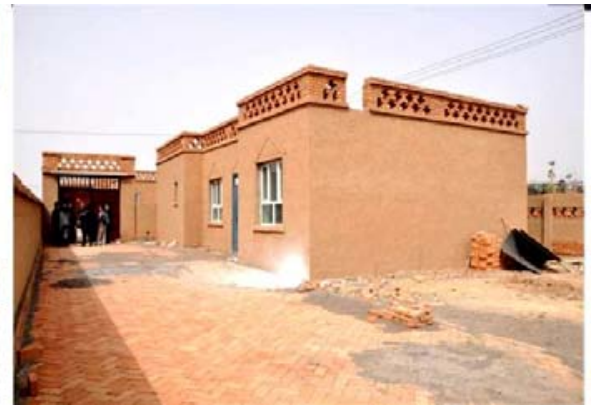

(b) Comfortable house

Figure 1. The Comfortable Housing Project.

Nowadays, local government in Turpan are developing a new house project to improve the housing conditions, this project is named as "Comfortable Housing Project". The comfortable house is

${ }^{\text {a }}$ Corresponding author : qdttzzh@163.com 
built by brick and concrete. Compared to the traditional adobe house, it is better in structure security [3]. However, it shows poor applicability to the local climate.(fig.1)

For this reason, the thermal environment of comfortable house and traditional adobe house is tested, and climate adaptability of these houses is analyzed in this paper. The result of this research may provide climate adaptability strategies for house design in Turpan.

\section{Test design}

\subsection{Test location}

Two houses are selected in this research, the first one (NO.1 test house) is comfortable house built buy government in 2012, and the other one (NO.2 test house) is adobe house built buy villages in 1964. The different of outdoor environment between two houses are shown in figure 1 .

To ensure comparability, these two houses are similar in roof materials and different in wall materials. Multiple roof is made of reed mat and soil, bear by Pitched wood truss system. The wall material of NO.1 test house is $370 \mathrm{~mm}$ thick brick wall, while the NO.2 test house is $700 \mathrm{~mm}$ thick Adobe wall. Thermal parameters of these materials are given in Table 1.

Table 1. Thermal properties of building envelope[4]

\begin{tabular}{|c|c|c|c|c|}
\hline \multirow{2}{*}{ Building envelope } & \multicolumn{2}{|c|}{ Roof materials } & \multicolumn{2}{c|}{ Wall materials } \\
\cline { 2 - 5 } & Reed mat & Raw soil & Brick & Adobe \\
\hline Thick $/ \mathrm{cm}$ & 0.5 & 20 & 37 & 70 \\
\hline Conductivity parameters $/(\mathrm{W} \cdot \mathrm{m}-1 \cdot \mathrm{K}-1)$ & 0.14 & 0.74 & 0.51 & 0.81 \\
\hline
\end{tabular}

\subsection{Test installation}

This test contents including four thermal parameters. They are outdoor air temperature, indoor air temperature and humidity, and wall surface temperature. Two test instruments are used. They are TR72ui two-channel air thermometer, and CENTER 309 four-channel contact thermometer.

\subsection{Test points}

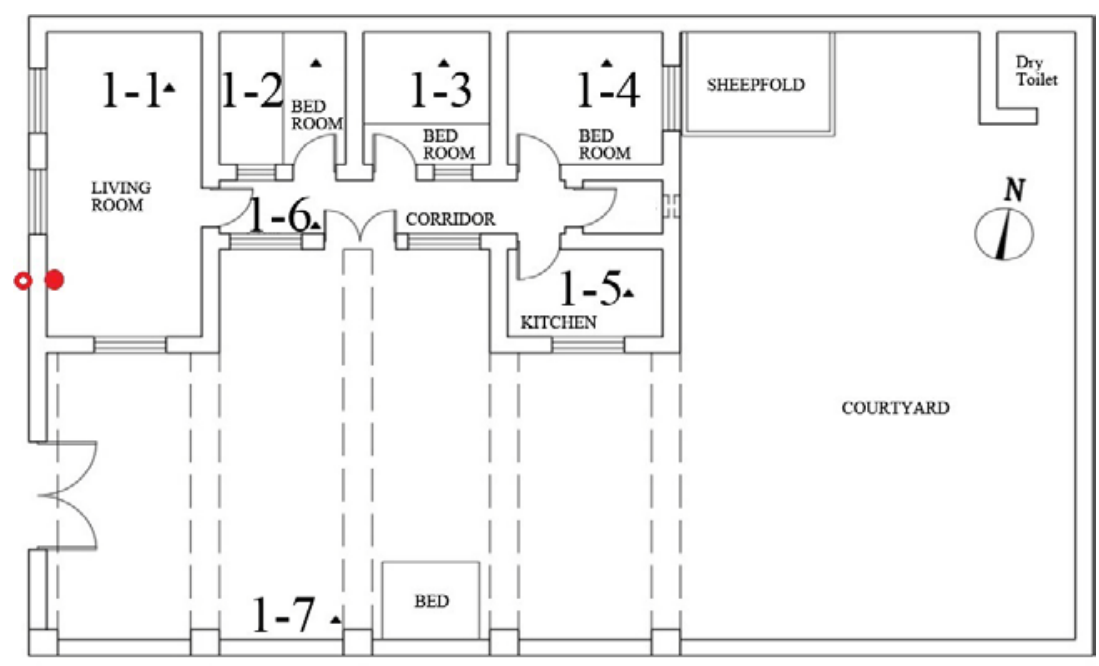

Figure 2. Test points in comfortable house. 
Figure 2 and 3 show the arrangement of test points in two houses. There are seven test points in comfortable house (NO.1 test house), including six indoor test points and one outdoor test point. All of these point are named by numbers as1-1, 1-2,1-3,1-4,1-5,1-6, and 1-7.

Six test points are arranged in traditional house (NO.2 test house), including five indoor test points and one outdoor test point. These test points are named as 2-1, 2-2, 2-3, 2-4, 2-5 and 2-6.

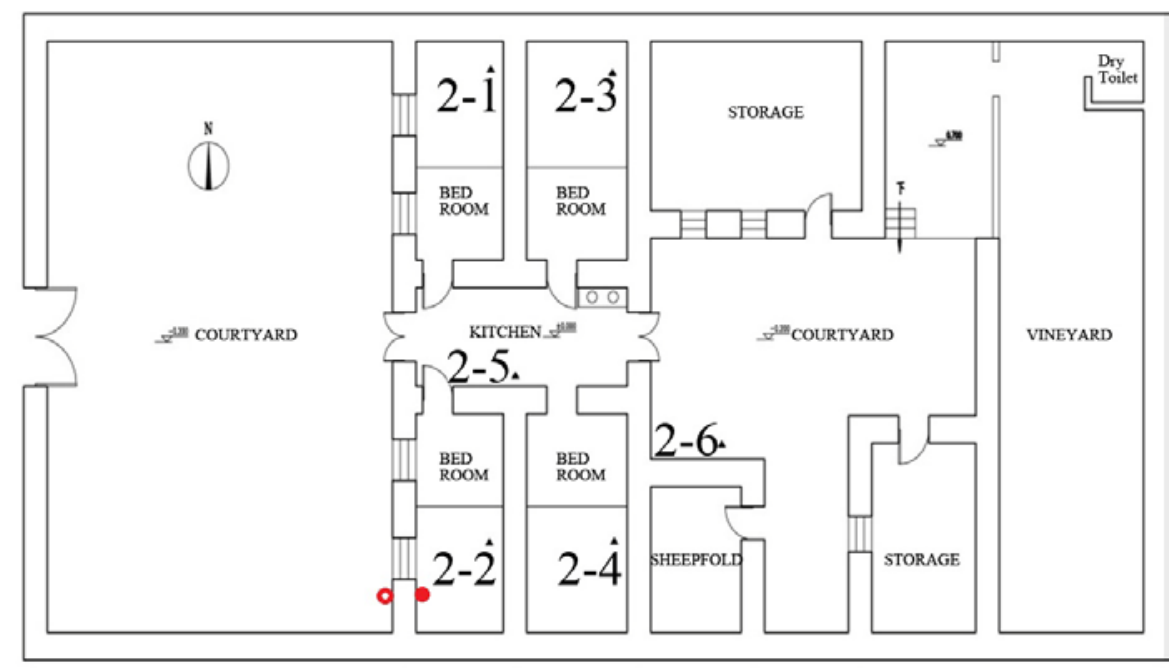

Figure 3. Test points in NO.2 test house.

\section{Results and analysis}

The test is taken in April, from $27^{\text {th }} 22: 00$ to $29^{\text {th }} 18: 00$. The thermal parameters are recorded by hours automatically. In all, 44 hourly data of Air temperature, air relative humidity, and surface temperature are gained.

\subsection{Air temperature and humidity}

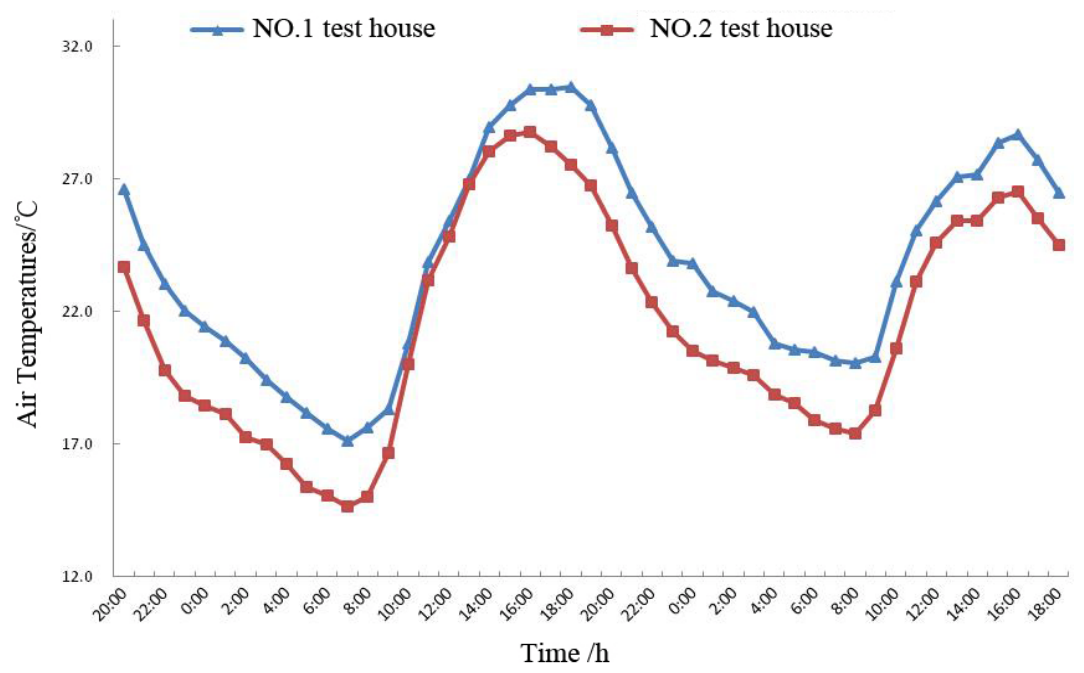

Figure 4. Hourly air temperatures in courtyard of two houses 
Figure 4 shows the difference in courtyard air temperatures between two houses. Based on the hourly air temperature, the average, maximum and minimum of air temperature in courtyards are calculated.

In NO.1 test house, the out door environment is hot and uncomfortable [5.6]. The average temperature is $23.8^{\circ} \mathrm{C}$, the maximum temperature is $30.5^{\circ} \mathrm{C}$, and minimum temperature is $17.1^{\circ} \mathrm{C}$. Comparatively, the result in NO.2 test house is $21.6^{\circ} \mathrm{C}, 28.8^{\circ} \mathrm{C}$, and $14.7^{\circ} \mathrm{C}$. Obviously, the outdoor thermal environment of NO.2 test house is cooler than NO.1. This result gives proof to the importance of courtyard, where trees and planting provide shade and cool air to the house. That is good to regulate the outdoor microclimate.

In order to make a contrast between the indoor thermal environments, two west rooms of these two houses are chosen. The hourly air temperatures and humidity of point 1-1 and 2-1 are shown in Figure 5. The result illustrates these:

1) The air temperature of point 2-1 is lower and more stable than point 1-1. This result shows the heavy Adobe wall is better than light brick wall in thermal environment stability.

2 ) The air relative humidity of point $2-1$ is a bit higher than point $1-1$. This result shows the adobe envelope is better for humidity adjustment than brick. However, two of the rooms are both dry and uncomfortable [7.8]. So strategies need to be taken for humidification.

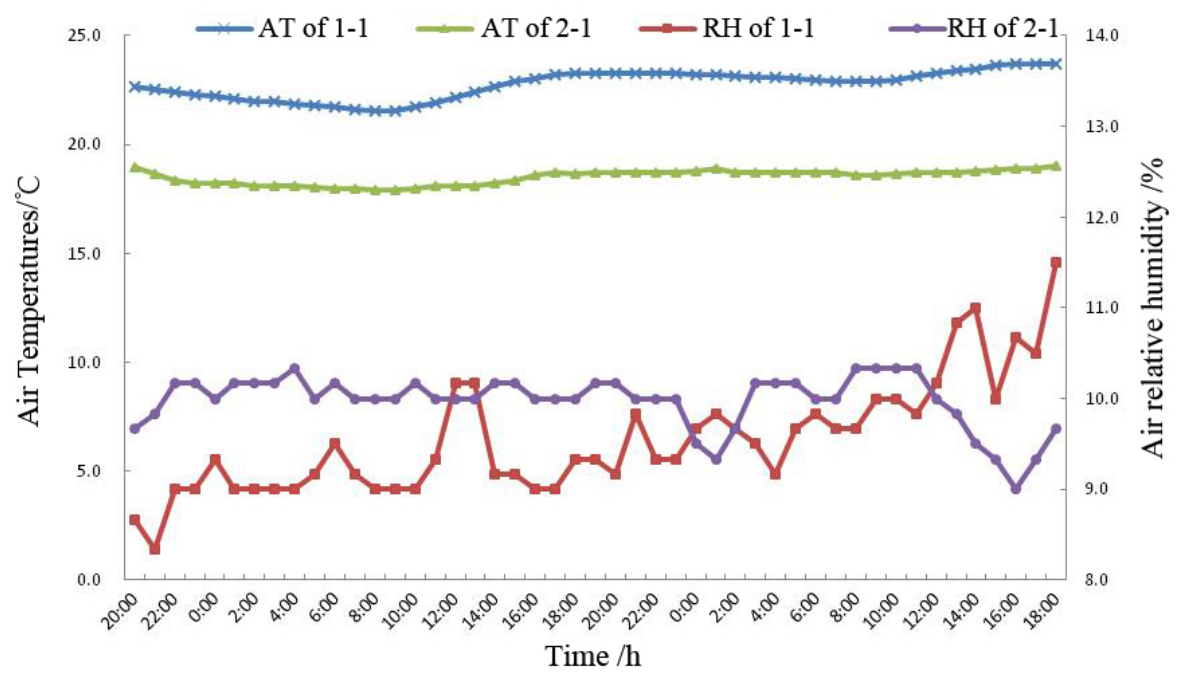

Figure 5. Indoor Hourly air temperatures of two houses

\subsection{Surface temperature}

To compare the thermal insulation of adobe wall and brick wall, hourly data of west wall surface temperature in two test houses is obtained (fig.6-7). Results of NO.1 test house are shown as following:

1) During the day time, the maximum outside surface temperature is $33.8^{\circ} \mathrm{C}$, it is higher than the outdoor air temperature, because of the vacancy of sunshade.

2) The indoor surface temperature is about $0.5^{\circ} \mathrm{C}$ higher than the indoor air temperature.

3) The average temperature of outside and inside surface temperature is $26.1^{\circ} \mathrm{C}$ and $23.0^{\circ} \mathrm{C}$. So the temperature difference is about $3^{\circ} \mathrm{C}$. 


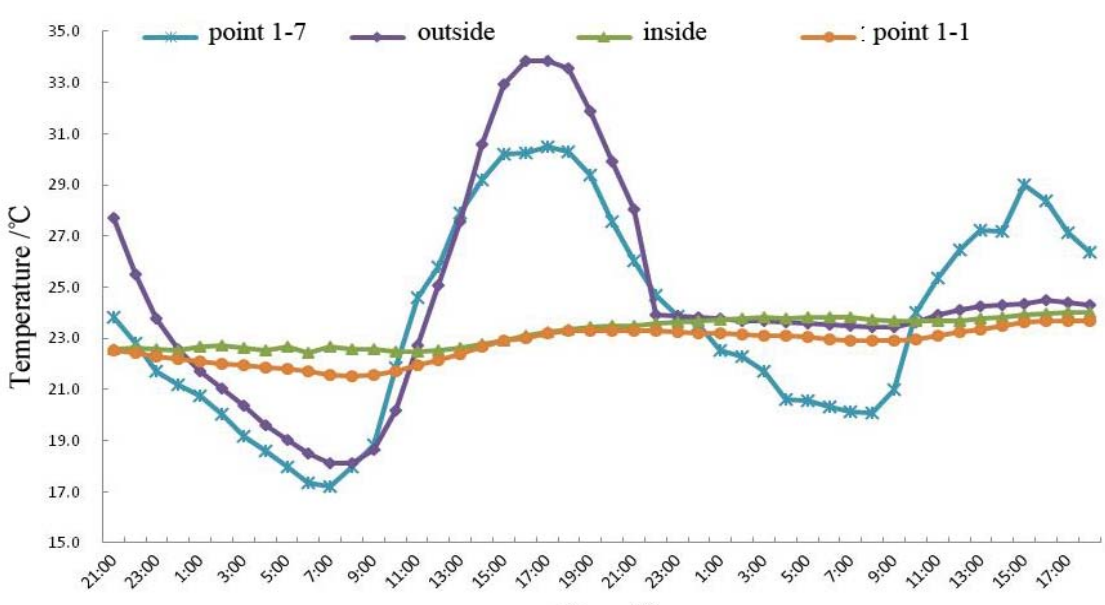

Time $/{ }^{\circ} \mathrm{C}$

Figure 6. Hourly temperatures of NO.1 house's west wall

Comparatively, results of NO.2 test house are shown as following:

1) During the day time, the outside surface temperature is lower than the outdoor air temperature. While at night, it is higher.

2) The maximum outside surface temperature is $20.5^{\circ} \mathrm{C}$, it is much lower than the NO.1 test house $\left(33.8^{\circ} \mathrm{C}\right)$. This difference shows the wonderful cooling effect of sunshade.

3) The average temperature of outside and inside surface temperature is $20.5^{\circ} \mathrm{C}$ and $19.2^{\circ} \mathrm{C}$. So the temperature difference is about $1.3^{\circ} \mathrm{C}$. While the difference in NO.1 test house is $3^{\circ} \mathrm{C}$ as shown bove. Therefore, the brick wall is better in heat insulation than adobe wall.

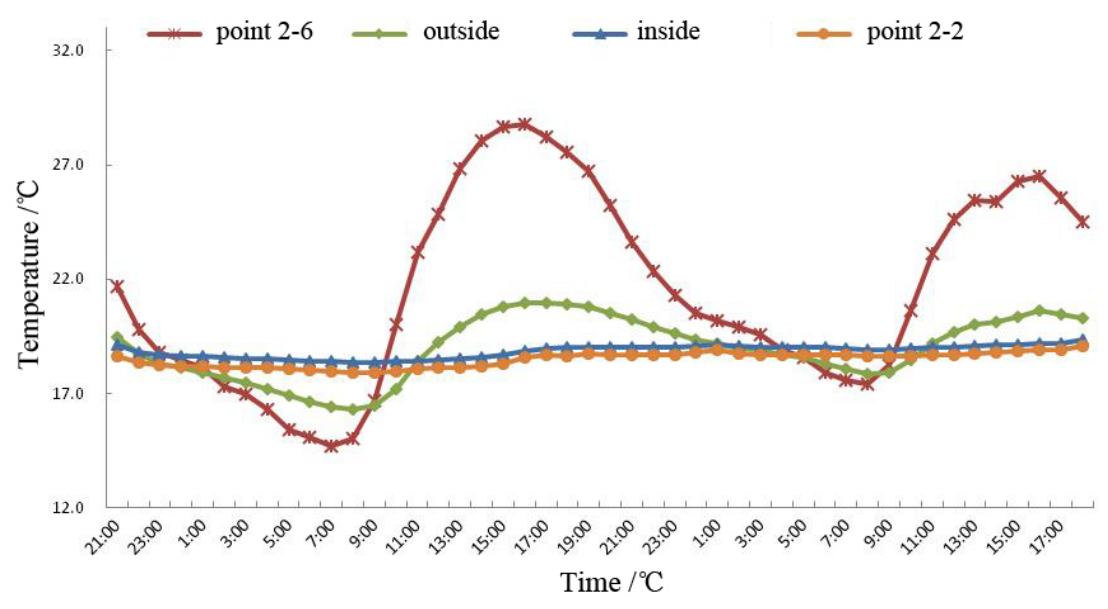

Figure 7. Hourly temperatures of NO.2 house's west wall

\section{Conclusion}

In the paper, thermal environment of comfortable house and traditional adobe house is tested, and the results are summarized as these:

(1) Planting in courtyard is good for shade and cooling, it is a useful strategy of outdoor microclimate regulation.

(2) Heavy envelope is better in thermal stability than light one.

(3) Adobe envelope is better for humidity adjustment than brick, but the indoor humidity environment is dry and uncomfortable in Turpan, so strategies need to be taken for humidification. 
(4) The brick wall is better in Heat insulation than adobe wall.

In conclusion, the climate adaptability of these two kinds of houses is obtained as following:

1) Traditional adobe house show climate adaptability in many aspects. Firstly, courtyard is one of the most important parts of traditional house, where the trees and plantings provide shade and cool air to villagers in hot summer. Secondly, the heavy adobe envelope is excellent heat accumulator, so it will absorb excessive heat in summer and release heat in winter; as a result, ensure a stable indoor thermal environment. Finally, the building material is mainly made by earth or wood, these materials are cheap, easy to obtain in Turpan, and can be recycled into new materials.

2) Compared with traditional adobe house, the comfortable house is better in structure security, but there are still some disadvantages. Firstly, the importance of courtyard is ignored, without the sunshade of plants, house expose completely to the hot sunshine. Secondly, the light brick envelope may meet the requirements of thermal isolation in winter, but it would not insulate the strong solar radiation in summer. So the indoor thermal environment in summer would be uncomfortable. Finally, the produce process of brick material increase the consumption of precious clay resources, and the emission of carbon. Clearly, the comfortable house shows poor applicability to the hot climate.

\section{Acknowledgement}

Thanks for the support of the National Natural Science Fund (NO. 51408479). Thanks for the support of the Natural Science Fund of education department (NO.14JK1407).

\section{References}

1. He Wenfang, LIU Jiaping, Shi Hongru. Thermal environment Of Uygur Traditional house based on migration custom. Journal of Building Science,(32)2016

2. He Wenfang, Bai Hui, Liu Jiaping. Field Test Study on Summer Thermal Environment of Thr Traditional Residential in Turpan. Acta Energiae Solaris Sinica, 35(2012)

3. HU Rong-rong. The changing course and development of the rural houses in mountain area in southern Shaanxi[J].Journal of Xi'an University of Architecture \& Technology(Natural Science Edition), 41(2009)

4. LIU Da-long. Investigation of thermal environment for Yinchuan traditional dwelling building in winter. Journal of Xi'an University of Architecture \& Technology, 42(2010)

5. S. Wijewardane, M.T.R. Jayasinghe. Renewable Energy, 33(2008)

6. Givoni, B(1976), Man, Climate and Architecture, Second Edition, Applied Science Publishers, London.

7. ANSI/ASHRAE Standard55-2004. American Society of Heating, Refrigerating and AirConditioning Engineers, Inc.

8. Michael Humphreys, Outdoor temperatures and comfort indoors[J]. Building Research and Practice, March/April, (6)1978

9. Andrew Baldwin, Chi-Sun Poon, Li-Yin Shen, et al. Designing out waste in high-riseresidential buildings: Analysis of precasting methods and traditional construction .Renewable Energy. 34 (2009)

10. Nieeolo Aste, Adriana Angelotti, Miehela Buzzetti . The influence of theextemal walls thermal inertiaon the energy Performance of well insulated buildings .Energy and Buildings, 41 ( 2009 ) 